\title{
RBEP
}

\section{A dialética inclusão/exclusão na experiência do programa UFGInclui}

Anita Cristina Azevedo Resende,

Edna Mendonça Oliveira Queiroz,

Gina Glaydes Guimarães Faria

\section{Resumo}

Apresenta uma análise dos dados da pesquisa "As contas da dialética inclusão/exclusão: a experiência das cotas na UFG", em desenvolvimento na Faculdade de Educação da Universidade Federal de Goiás (UFG), com o objetivo de apreender as mediações e os processos implicados nessa dialética a partir da experiência dos alunos ingressantes em 2009 pelo Programa UFGInclui. A pesquisa revela tendências que apontam - por dentro do próprio grupo dos estudantes ingressantes pelo Programa UFGInclui - que a desigualdade socioeconômica e suas consequências se recolocam, acentuando-se e expressando novos patamares de exclusão. Assim, entre os "excluídos", a exclusão se reproduz e a inclusão se efetiva de maneira desigual.

Palavras-chave: ações afirmativas; dialética inclusão/exclusão; Programa UFGInclui. 


\section{Abstract \\ The dialectic inclusion/exclusion in experience of the UFGInclui Program}

This article presents an analysis of the data from the research "The accounts of dialectic inclusion/exclusion: the experience of the quotas in UFG" undergoing in the Education College at the Federal University of Goiás (UFG), with the purpose of understanding the mediations and the processes involved in this dialectic, from the experience of students entering, in 2009, through the UFGInclui Program. The research revealed trends that suggest that - within the group of students who were admitted through the UFGInclui Program - the socio-economic inequality and its consequences reset themselves, aggravating and expressing new levels of exclusion. Therefore, among the "excluded", the exclusion reproduces itself, and the inclusion is achieved unevenly.

Keywords: affirmative action; inclusion/exclusion dialectic; UFGInclui Program.

Ainda recentes no Brasil, as políticas de ação afirmativa se estabelecem no diapasão entre o reconhecimento de processos excludentes que constituem a sociedade brasileira e a busca de compensação/reparação desses processos. A compreensão das determinações materiais e históricas da desigualdade social, as possibilidades de superação dessas determinações, os objetivos da educação, entre outros, são desafios que se recolocam quando estão em causa relações, processos e estruturas inerentes e fundantes do modo de produção capitalista. Dessa perspectiva, pode-se considerar então que as políticas afirmativas, ao partirem do reconhecimento e da busca de compensação de modos estruturais de exclusão e desigualdade, encontram entraves ao seu desenvolvimento dentro de suas próprias regulações.

No Brasil, a discussão acerca das ações afirmativas, principalmente no âmbito acadêmico e no político, se generalizou e ganhou destaque a partir de 1990. O estabelecimento da cota mínima de mulheres para as candidaturas nos partidos políticos e a criação do Grupo de Trabalho Interministerial para a Valorização e Promoção da População Negra em 1995, ou o Programa Nacional de Direitos Humanos (PNDH), de 1996, que objetivava "formular políticas compensatórias que promovam social e economicamente a comunidade negra" (Brasil, 1996, p. 30, apud Moehlecke, 2002, p. 207), podem ser tomados como emblemas dos marcos legais iniciais destinados ao estabelecimento dessas políticas compensatórias.

A partir deles, tornou-se cada vez mais pública a necessidade de o governo federal, a sociedade civil e o setor privado combaterem a 
discriminação e a desigualdade racial, impulsionando a discussão acerca de políticas de ações afirmativas; assim, do acirrado debate entre defensores e opositores, resultou um escopo reducionista dessas ações afirmativas, tomadas quase que exclusivamente como política de cotas (Pinto, 2006). Foi principalmente dessa perspectiva que as universidades brasileiras implantaram cotas raciais.

Desde 2002, com a atuação inicial da Universidade do Estado do Rio de Janeiro (Uerj) e da Universidade do Estado do Norte Fluminense (Uenf), tornou-se cada vez mais frequente nas universidades públicas brasileiras a adoção de alguma modalidade de reserva de vagas que privilegiam grupos diferenciados, como afrodescendentes, índios, quilombolas, estudantes egressos de escolas públicas, entre outros, para o ingresso nos cursos de graduação.

Nesse contexto, a Universidade Federal de Goiás (UFG) aprovou em 2008 e implantou no concurso vestibular de 2009/1 o Programa UFGInclui, ${ }^{1}$ apresentado como "uma proposta de inclusão" assim justificada: a Universidade é uma instituição plenamente inserida nos contextos sociais, político e econômico do local onde ela se instalou. Enquanto tal, ela reflete as condições da configuração da existência humana que são produzidas nesses contextos. No caso brasileiro, essas condições são marcadas por profundas desigualdades sociais quanto ao acesso e usufruto dos bens materiais e culturais que são produzidos socialmente. No que diz respeito à educação, essas desigualdades se manifestam pela existência de segmentos significativos da sociedade que não têm acesso a um ensino de qualidade ou sofreram historicamente alguma forma de exclusão social, como os negros (pretos e pardos), índios e negros quilombolas [...] Estes estudantes ficam, então, em desigualdade perante o processo seletivo e estes são os jovens que estudaram o ensino básico em escolas públicas ou que pertencem aos recortes étnicos e raciais que envolvem os negros, índios e negros quilombolas. (UFG, 2008a, p. 5).

O Programa considerava ainda que a "exclusão social" ou a "desigualdade" seriam tanto mais graves em Goiás porque apenas 14,71\% dos 775.000 jovens com idades entre 18 e 24 anos teriam acesso ao ensino superior. E mais: que, na Região Centro-Oeste, 72,6\% dos jovens realizavam o ensino médio em escola pública e constituíam um contingente predominantemente situado nas classes C, D e E; que as informações fornecidas pelo Centro de Seleção acerca dos inscritos e classificados nos processos seletivos no período de 2004 a 2008 apontavam para "uma predominância dos estudantes negros (pretos e pardos) como oriundos das classes de menores rendimentos"; que os negros (pretos e pardos) "têm mais dificuldade para se classificarem nos cursos da UFG"; que haveria "correlação entre anos de estudos e o aumento do rendimento mensal"; que "aqueles que estudaram nas escolas públicas de ensino médio possuem mais dificuldade para se classificarem nos cursos da UFG" (UFG, 2008a, p. 13-20).

A partir do reconhecimento desses processos, a UFG propôs-se "amenizar, no momento do processo seletivo, a desigualdade existente no processo de formação cultural entre os estudantes que fazem parte
${ }^{1}$ Cf. Seminário UFGInclui (2011). 
de agrupamentos sociais desfavorecidos e aqueles que não enfrentaram as dificuldades inerentes a esses jovens" (UFG, 2008a, p. 3). Para tanto, implantou o Programa UFGInclui para promover "a inclusão de estudantes de escolas públicas, negros que estudaram em escolas públicas, indígenas e negros quilombolas, por um tempo determinado" (UFG, 2008a, p. 1) de 10 anos, na proporção de 10\% das vagas destinadas a estudantes oriundos de escola pública, 10\% para negros oriundos de escola pública, uma vaga para negros quilombolas e uma vaga para indígenas (essas últimas acrescidas no quantitativo de vagas de cada curso onde houvesse demanda para os casos) (UFG, 2008a, p. 8), de modo que o programa teve início em 2009, e, aprovados no processo seletivo do vestibular, em março desse mesmo ano, ingressaram na UFG os primeiros estudantes contemplados com cotas. Ao tempo, na Faculdade de Educação da UFG também tinha início em 2009 a pesquisa intitulada "As contas da dialética inclusão/exclusão: a experiência das cotas na UFG", ${ }^{2}$ com o objetivo de investigar o desenvolvimento e os entraves desse Programa, privilegiando a dialética inclusão/exclusão na experiência dos estudantes que ingressaram na universidade nessa modalidade de ação afirmativa. Esse ponto de partida considerava a inclusão/exclusão enquanto expressão estrutural da igualdade/desigualdade referida a processos sociais reciprocamente determinados e contraditoriamente relacionados.

\section{As cotas na UFG: para quem?}

Originados na realidade material e estabelecidos a partir da contradição fundamental entre trabalho e capital, os processos sociais de exclusão e inclusão se produzem e reproduzem com uma complexidade cada vez maior tanto do ponto de vista objetivo quanto do subjetivo.

Os processos e estruturas que produzem a inclusão/exclusão são materiais e objetivos, no entanto, quando internalizados, podem parecer naturais, alcançando a consciência do indivíduo e minando sua resistência. Assim, tais processos não estão referidos somente aos objetos produzidos socialmente, mas também aos valores, às formas de relação social, aos sentidos e aos significados, isto é, aos sujeitos sociais e à sua subjetividade.

${ }^{2}$ Trata-se de um estudo longitudinal dos alunos que ingressaram na Universidade Federal de Goiás (UFG) pelo Programa UFGInclui. A este projeto estão vinculados três subprojetos: "Programa UFGInclui: mediações familiares e formação dos jovens" "Estudo do sucesso/fracasso escolar na trajetória acadêmica dos estudantes que ingressaram na UFG por meio do Programa UFGInclui" e "O espetáculo das cotas e a imprensa: as ideias e debates sobre as políticas afirmativas nas universidades públicas (2009-2015)"

A dialética inclusão/exclusão gesta subjetividades específicas que vão desde o sentir-se incluído até o sentir-se discriminado ou revoltado. Essas subjetividades não podem ser explicadas unicamente pela determinação econômica, elas determinam e são determinadas por formas diferenciadas de legitimação social e individual, e manifestam-se no cotidiano como identidade, sociabilidade, afetividade, consciência e inconsciência. Em síntese, a exclusão é um processo complexo e multifacetado [...]. (Sawaia, 2006, p. 9).

Desse ponto de vista, caso se tome por base a análise do questionário socioeconômico aplicado pelo Centro de Seleção da Universidade Federal de Goiás a todos os inscritos e aprovados no vestibular 2009/1 pelo sistema 
universal e pelo Programa UFGInclui, já se pode antever essa intrincada dialética inclusão/exclusão caracterizada no perfil dos jovens candidatos a serem "incluídos" em razão do reconhecimento de sua "exclusão".

Os estudantes aprovados no vestibular pelo Programa UFGInclui apresentam um perfil socioeconômico e racial substantivamente desigual se comparado com o perfil dos aprovados pelo sistema universal. A renda familiar da maioria dos estudantes aprovados pelo sistema universal $(58,4 \%)$ fica entre $\mathrm{R} \$ 1.660,01$ e $\mathrm{R} \$ 8.300,00$, sendo que 10,8\% do total têm renda acima de R\$ 8.300,00. Entre os convocados pelo Programa UFGInclui, 65,4\% têm renda de até $\mathrm{R} \$ 1.660,01$, chegando esse percentual a 90,8\%, considerando-se o limite de $\mathrm{R} \$ 3.320,00$. Com renda familiar acima dessa faixa estão situados apenas 9,3\% desses estudantes.

Essa mesma tendência pode ser observada quando se considera a cor declarada pelos estudantes. Daqueles que ingressaram pelo sistema universal, a maioria (56,8\%) declarou-se branca e 33,1\%, pardos; os pretos somaram apenas 4,1\%. Em relação aos estudantes que ingressaram pelo Programa UFGInclui, apenas 12,7\% declararam-se brancos, sendo que $37,3 \%$ declararam-se pardos e $47,3 \%$, pretos. Independentemente dos processos objetivos e subjetivos implicados no critério de autonomeação, a vinculação entre classe e etnia no Brasil é por demais evidente nas suas imbricações com a classe social.

Essa desigualdade evidencia-se também quando se considera a escolaridade dos pais. Ou seja, 35,2\% dos pais ou responsáveis e 26,5\% das mães ou substitutas dos estudantes que ingressaram pelo sistema universal têm curso superior completo ou de pós-graduação. Em relação aos que ingressaram pelo Programa UFGInclui, esse índice altera-se de maneira substantiva: apenas 10,0\% dos pais ou responsáveis e 15,4\% das mães ou substitutas acessaram esse nível de ensino. Da mesma forma, quando se considera a ordem de prioridades no orçamento doméstico nas famílias dos estudantes aprovados pelo sistema universal, a instrução se apresenta em segundo lugar (28,9\%), antecedida somente pela alimentação (44,9\%); nas famílias dos estudantes ingressos pelo Programa UFGInclui, ela está relacionada em terceiro lugar, com a alimentação aparecendo em primeiro na maior parte das famílias $(66,2 \%)$ e a moradia $(14,2 \%)$ em segundo. Tendencialmente, aqui se entrecruzam, na priorização da educação dos filhos, duas ordens de determinações: a renda familiar e as possibilidades educacionais às quais os próprios pais tiveram acesso.

É importante observar que o acesso dos jovens estudantes pelo Programa UFGInclui comporta algumas especificidades. Pelos critérios estabelecidos pelo programa e em razão da relação candidato/vaga, o preenchimento das vagas disponíveis de cursos diferentes se dá de maneira específica. Desse modo, em alguns cursos não foi necessário acionar o sistema de cotas, visto que os alunos inscritos alcançaram o ponto de corte necessário para ingressar pelo sistema universal (Ciências Contábeis, Zootecnia, Engenharia Florestal, Biblioteconomia, Estatística, Educação Musical, Filosofia, Licenciatura em Física, Bacharelado em Química). De outra parte, em cursos cuja concorrência no ingresso é maior (Medicina, 
Odontologia, Direito e Engenharia Civil), o percentual de 20\% previsto no Programa foi integralmente acionado.

Essas especificidades elucidam processos que merecem ser considerados. Já de início, tomando em consideração os estratos anteriormente elencados (renda familiar, cor/raça, escolaridade dos pais, gastos com a escolaridade), no grupo dos estudantes ingressos nos cursos mais concorridos (que utilizaram o percentual de $20 \%$ de vagas previsto no programa) e no grupo dos estudantes que ingressaram nos cursos menos concorridos (que não utilizaram este percentual), ficam evidenciados processos de desigualdade e exclusão que se produzem e reproduzem entre os dois grupos e dentro do mesmo grupo de estudantes.

A renda familiar da maioria dos estudantes aprovada pelo sistema universal dos cursos mais concorridos (74,6\%) fica entre $\mathrm{R} \$ 1.660,01$ e R\$ 8.300,00, sendo que 29,8\% do total desse grupo têm renda familiar acima de R\$ 8.300,00. Contudo, entre os convocados para os mesmos cursos pelo Programa UFGInclui, 42,4\% têm renda de até R $\$ 1.660,01$, chegando a 75,7\% considerando-se a faixa de R\$3.320,00; com renda familiar acima desse patamar estão 21,1\% dos estudantes. De outra parte, analisando a renda familiar dos que ingressaram pelo sistema universal nos cursos menos concorridos, 68\% têm renda de até R\$3.320,00, com 29,3\% apresentando renda superior a essa faixa. Já a renda máxima de $100 \%$ dos estudantes que ingressaram pelo Programa UFGInclui é de $\mathrm{R} \$ 3.320,00$, observando-se que $84,7 \%$ apresentam renda de até $\mathrm{R} \$ 1.660,00$.

Nota-se então que, comparadas com o perfil do conjunto dos estudantes independentemente do curso referido, as porcentagens variam de maneira substantiva e apontam uma estratificação entre os que ingressaram pelo Programa UFGInclui e pelo sistema universal e, dentro dos que ingressaram pelo sistema de cotas, entre aprovados em cursos mais ou menos concorridos. E essas estratificações não se limitam à renda familiar.

Em relação à cor dos estudantes, entre aqueles que ingressaram pelo sistema universal nos cursos mais concorridos, a maioria (66\%) declarou-se branca e 25,7\%, pardos; os pretos somam apenas 2,6\%. Em relação aos que ingressaram nos mesmos cursos pelo Programa UFGInclui, apenas $16,7 \%$ declararam-se brancos, 53\%, pardos e 27,3\%, pretos. Esse quadro se modifica diante dos dados relativos aos cursos mais concorridos: 50,2\% dos aprovados pelo sistema universal declararam-se brancos e 37,7\%, pardos; os pretos somaram apenas $4 \%$. Nos cursos menos concorridos, os pretos são a grande maioria, com $92,3 \%$, os pardos $7,7 \%$, sem ter sido constatada a presença de brancos.

Quando se analisa a escolaridade dos pais ou responsáveis, a tendência se confirma: os pais dos estudantes que ingressaram nos cursos mais concorridos têm maior escolaridade se comparados aos dos cursos menos concorridos. Assim, 57,4\% dos pais ou responsáveis e 59,7\% das mães ou substitutas dos estudantes que ingressaram nos cursos mais concorridos pelo sistema universal têm curso superior completo ou de 
pós-graduação. Em relação aos que ingressaram pelo Programa UFGInclui este índice se altera: apenas $21,2 \%$ dos pais ou responsáveis e $24,3 \%$ das mães ou substitutas têm esse nível de escolaridade. Ainda, tomando os percentuais dos estudantes que ingressaram em cursos menos concorridos pelo sistema universal, 27,4\% dos pais ou responsáveis e 31,5\% das mães ou substitutas têm escolaridade superior completa ou pós-graduação. Já para os que ingressaram pelo Programa UFGInclui, este quantitativo cai acentuadamente, pois nenhum pai ou responsável apresenta esse nível de escolaridade e somente $15,4 \%$ das mães ou substitutas o apresentam.

Em relação às prioridades de gasto no orçamento familiar, a maioria das famílias dos estudantes aprovados pelo sistema universal nos cursos mais concorridos (53\%) posiciona a instrução em primeiro lugar em relação a outros itens, como alimentação, médicos/dentistas, lazer/ viagens e outros. Nas famílias dos estudantes ingressos nesses mesmos cursos pelo Programa UFGInclui, a instrução fica em segundo lugar, pois a maior parte das famílias $(59,1 \%)$ coloca a alimentação em primeiro. Em relação aos cursos menos concorridos, a maior parte das famílias dos aprovados pelo sistema universal $(53,9 \%)$ coloca a alimentação em primeiro lugar, e a instrução aparece em segundo. Nos convocados pelo Programa UFGInclui, a instrução aparece em terceiro lugar, após alimentação e moradia..

Esses indicativos reafirmam tendências que apontam a evidente desigualdade entre os estudantes aprovados pelo sistema universal e os que ingressam pelo Programa UFGInclui e confirmam as desigualdades de classes e de oportunidades. Mas, para além disso, merece ainda destaque o fato de que, por dentro do próprio grupo dos estudantes ingressantes na UFG pelo Programa UFGInclui, a desigualdade socioeconômica e suas consequências se recolocam. Desse modo, por exemplo, a renda familiar dos convocados pelo Programa UFGInclui dos cursos mais concorridos apresenta-se bem mais elevada do que a renda dos convocados para os cursos menos concorridos dentro do mesmo programa. Observada a cor, nota-se que, entre os ingressantes pelo sistema de cotas dos cursos mais concorridos, somente 2,6\% são pretos; nos cursos menos concorridos, esse percentual é de 92,3\%. Quanto à escolaridade, entre os ingressantes pelo sistema de cotas nos cursos mais concorridos, o ensino dos pais encontra-se na faixa dos 50\%, contra $20 \%$ entre os ingressantes dos cursos menos concorridos. É importante também observar que a alimentação é listada, entre os estudantes do Programa UFGInclui que ingressaram nos cursos menos concorridos, antes da instrução, ao contrário dos ingressantes nos cursos mais concorridos do programa, de maneira que, em sentido amplo, é possível afirmar que as tendências que se colocam no interior dos dois grupos se mantêm quando contrastadas com os cursos mais ou menos concorridos. Contudo, elas se acentuam e expressam novos patamares de exclusão por dentro do mesmo grupo de jovens aos quais são oferecidas oportunidades compensatórias dos processos de exclusão que marcaram suas vidas. Entre os "excluídos", a exclusão se estabelece e a inclusão se efetiva de maneira desigual. 


\section{Com a palavra, os alunos do Programa UFGInclui}

As entrevistas realizadas com alunos participantes do Programa UFGInclui provenientes de escolas públicas e que ingressaram nos cursos de maior competitividade na UFG no ano de 2009, utilizando portanto o maior número de cotas (Direito, Medicina, Odontologia e Engenharia Civil), permitem relevar a construção material da desigualdade e as formas de atualização da exclusão na experiência de "cotista" da UFG.

Estudante do curso de Odontologia, Lucas ${ }^{3}$ sempre frequentou escola pública. Seus pais não cursaram universidade, porém, sempre tiveram essa meta para os filhos. Morava em uma cidade do interior bem próxima à capital, transferindo-se para um colégio público de Goiânia. Todos os dias, percorria de ônibus um longo trajeto para estudar. Tem uma ótima relação com a mãe e a considera responsável por ter conseguido estar hoje na faculdade.

Considera-se uma pessoa com poucas amizades, quase todas ainda da infância. Não é de sair muito, é mais caseiro. Tem mais facilidade de se relacionar com pessoas mais velhas. Assim, tem amigos de mais idade, pois sair com a turma à noite, ir a barzinhos não são programas que goste de fazer, não porque ache errado, mas porque se sente constrangido em alguns lugares, considera-se tímido. É religioso e gosta muito de ir à igreja.

Depois do ensino médio, fez um ano de cursinho em um colégio particular. Sobre seu processo de aprendizagem no ensino médio, diz que não teve bom aproveitamento. Quando foi para o cursinho, percebeu a enorme defasagem que havia entre a escola pública e a particular:

[...] quando eu cheguei no cursinho, tinha um monte de coisa que eu não sabia. Por exemplo, eram coisas que eu tinha que revisar, eu não sabia, entendeu? Eu não sabia. Assim, acaba que tem coisas que a gente deixa um pouco pra trás e de vez em quando vai estudar lá, a bioquímica, ainda tem que ir lá na química pra tentar aprender aquele negócio lá atrás que eu não tinha aprendido.

No cursinho, já percebia as "piadinhas" dos colegas sobre as cotas:

é cota pra negro, é cota pra num sei o quê, é cota pra isso, é cota pra escola pública. Aí, tinha as cotas pra quem morava perto da UnB, não tinha? [...] e é cota mais pra corintiano e cota mais pra aquilo (risos) e daí assim, às vezes, a gente percebia essas piadinhas, mais, assim, eu sempre fiquei calado - fiquei na minha. Às vezes eu percebia, assim, que os alunos da escola particular... porque, assim, o menino está ali no cursinho e aí ele quer passar, ele num está nem aí se o Brasil está crescendo, ele num está nem aí se a classe dominante está na faculdade ou não, ele num está nem aí se a maioria dos negros estão na classe baixa, não consegue entrar na universidade porque não tem escola boa e acessível - a escola pública muitas vezes não é de boa qualidade -, ele num está nem aí, ele quer é passar, ele num está nem aí pro resto. Ele está ali pra ele, porque ele está ali dois anos, três anos, tentando cursinho pra medicina e odontologia e ele num está nem aí pra cotas. Então ele cria um certo sentimento de raiva das cotas por causa disso, né? Começa a criticar as cotas, tem um sentimento de raiva assim por causa das cotas! 
Considera as cotas de grande importância porque é possível que, com a entrada de alunos diferenciados, alguma mudança possa acontecer: eles poderão "fazer alguma diferença". Para ele, não dá para esperar que as escolas públicas melhorem. Relata:

Eu acho assim: [...] o ensino público não tem qualidade. Então, como que ele vai entrar numa universidade? Eles estudam a vida inteira numa escola pública, aí, depois, ele tem que entrar numa universidade particular porque ele não consegue entrar na faculdade pública; e o menino da particular estuda na particular a vida inteira e vem fazer na pública. Então, assim, pra não ter cotas nas faculdades federais, nas estaduais, eu acho que o governo, a educação pública teria que melhorar muito. Enquanto não tiver essa condição, de melhorar essa educação - talvez tenham condição, mas não façam, né? -, enquanto não melhorar essa educação, eu acho que as cotas são justas.

Jackson, aluno do curso de Engenharia Civil, também morava em uma pequena cidade próxima de Goiânia. Seus pais estudaram até a $5^{\mathrm{a}}$ série e se empenharam muito para que os dois filhos pudessem ter uma formação melhor do que a deles. De sua família, apenas um tio e uma tia cursaram o ensino superior. Sempre estudou em escola pública e, quando morava na sua cidade, conciliava trabalho e estudo. Agora dedica-se apenas aos estudos, mas não gosta de depender do seu pai para tudo. Reconhece as dificuldades dos pais para manter a família.

No entanto, o projeto familiar previa uma vida diferente dos pais para os filhos e, para isso, os pais estavam dispostos a investir. Jackson relata:

Eles [os pais] diziam: "olha a gente nunca teve e a gente não quer essa vida que a gente tem [para vocês]; a gente vai apoiar no que for preciso. Se você não passar na universidade federal e quiser uma particular a gente vai pagar, a gente vai dar um jeito, mas você vai continuar seus estudos, você não vai parar, não!".

Nunca foi reprovado na escola e sempre se considerou um bom aluno. No ensino médio, transferiu-se para uma boa escola pública de Goiânia. Não tem grandes dificuldades na universidade, mas reconhece que é preciso "correr atrás". Diz que é diferente para quem sempre teve uma boa escola. Sua primeira reprovação na escola foi no primeiro semestre do primeiro ano do curso superior.

Como Jackson e Lucas, José também é de uma pequena cidade próxima a Goiânia e cursa Medicina. Filho de família evangélica, nasceu e sempre morou em um bairro "humilde" da cidade. Sempre manteve boa relação com os professores na sua vida escolar, nunca teve maiores dificuldades em relação às disciplinas e sempre teve inclinação para Ciências e Matemática. Acredita que o Programa UFGInclui foi um instrumento que Deus colocou em sua vida para realizar seu sonho de cursar Medicina, que ele achava impossível. Referiu-se aos sinais de Deus que indicaram sua inscrição ao vestibular ("tudo aconteceu em uma semana").

Expõe que o estudo é muito valorizado por sua família e que seus pais sempre orientaram os filhos no sentido de se esforçarem para ter 
sucesso na escola. Algumas vezes é obrigado a faltar às aulas devido ao trabalho, que considera muito importante para sua vida. Quando tem dificuldades, conversa com os professores, que, até o momento, têm se mostrado compreensivos e colaboradores.

Relata que o Programa UFGInclui é necessário, porque, de fato, "pela história do negro no Brasil, não há outro jeito de se fazer justiça". E complementa: "um escravo não deixa nada pros seus filhos". Afirmou mais de uma vez que, há apenas quatro gerações, os negros eram escravos; colocou seu bisavô na condição de escravo, indagando: "o que ele teria deixado para seus filhos?" Considera a escola no Brasil elitista e que a escola pública não oferece bom ensino, sobretudo na área de Ciências e Matemática, exatamente as disciplinas que considera mais importantes. Ele próprio estava estudando matérias do ensino médio "por fora" para dar conta de acompanhar o curso, embora tenha afirmado não ter maiores dificuldades para acompanhar as matérias.

Disse que sua turma é muito boa, menos "arrogante" do que turmas anteriores. Ilustra isso ao referir-se a uma disciplina na qual os alunos desenvolvem projetos junto às "pessoas mais carentes", e todos se sentem muito à vontade, entusiasmados. Segundo José, esta é a avaliação do professor da disciplina que tem trabalhado com outras turmas e não havia constatado tal envolvimento. José afirma que muitos fazem o curso apenas para ganhar dinheiro, o que não é o seu caso (faz "para ajudar"). Para ele, isso pode estar ocorrendo por causa da presença de estudantes oriundos dos meios "mais humildes", que passam por "certas situações" e entendem melhor a realidade (refere-se aos estudantes do UFGInclui).

Aluna do curso de Direito, Samanta mora, há três anos, em Goiânia, longe de sua família. Sua mãe, que não sabia ler, agora está sendo alfabetizada; seu pai é trabalhador de serviços de manutenção. Diz que sua relação com a mãe influiu e influi fortemente em sua vida - o fato de sua mãe ser de outra etnia é algo marcante para ela, que, por várias vezes, expressou o "interesse pelas causas das minorias étnicas".

Desde que veio para Goiânia, trabalha para se manter. Hoje, trabalha no setor de serviços no horário comercial. Em sua família, seus irmãos não se interessaram pelos estudos, que para ela são importantes. Até a oitava série, considerava-se uma ótima aluna; depois, no ensino médio, passou a estudar à noite e mudou seu comportamento, dedicando-se menos aos estudos. Começou um curso superior e estava muito satisfeita. Quando saiu o Programa UFGInclui, decidiu-se por fazer Direito. Não foi uma decisão fácil, desde que, para ela, as "possibilidades eram mínimas".

Tem enfrentado dificuldades na universidade. No primeiro semestre, não conseguiu aprovação em nenhuma disciplina, porque chegava atrasada por causa do trabalho. Muitas vezes, prefere faltar às aulas, pois os professores não gostam de atraso dos alunos. Matriculou-se, posteriormente, em apenas duas disciplinas e, ainda assim, tem tido problemas para acompanhar o curso. Não consegue conversar com os professores e, ao tratar com eles, "gostam de conversar 
alto para todos ouvirem". Enfim, não consegue se relacionar com os professores.

Samanta afirma que o Programa UFGInclui é muito bom e válido, e usa o mecanismo da culpa ao refletir sobre sua situação. Diz: "Só isso já é um grande passo para ajudar a gente, e acho que a gente tem que segurar mais, porque... é a gente mesmo que não tá dando conta disso, porque a instituição está dando. [...] Acho que é falta de incentivo da minha parte, mas eu gosto de vir pra faculdade."

Negro, casado, Paulo cursa Direito. Trabalha como funcionário público. É originário de família pobre, família grande. Nenhum membro de sua família tem curso superior - seus pais são semianalfabetos -, mas relata que sempre se interessou pelos estudos. Seus pais sempre "inculcaram" nele, desde criança, a importância de estudar "para se conseguir alguma coisa na vida". Sonhava seguir a carreira militar. Começou a trabalhar muito cedo (quando criança vendia salgados nas obras e foi "contínuo" em um banco).

Sempre estudou em escola pública. Após algumas tentativas frustradas de cursar o ensino superior (não conseguia se manter no curso por não ter dinheiro para pagar), conseguiu se formar. Considera-se "viciado em banco de universidade". Sempre teve interesse no curso de Direito e prestou várias vezes vestibular para esse curso, mas "nunca conseguiu passar". Em 2009, decidiu fazer novamente o exame, "só para ver como estava o vestibular" e optou pelo Programa UFGInclui. Para sua surpresa, foi aprovado.

Em um ano, acha que o curso já o transformou. Interessa-se muito pelos Direitos Humanos (em especial pela disciplina Sociologia). Reconhece-se como negro e sempre percebeu a discriminação de que foi vítima, desde criança. Sempre se viu isolado, especialmente à medida que ascendeu socialmente. Na universidade, sempre foi o único aluno negro na sala. No trabalho, também são "raríssimos" os negros: "quanto mais eu consigo uma ascensão, quanto mais eu subo um degrau, é menor a possibilidade de encontrar alguém como eu..."

porque antes, pra mim, era algo que... mesmo você vivendo desde criança, você vivendo... é...- como se diz? -, viver chacota, viver tudo aquilo ali, você tachado de uma coisa, de outra, parece que, quando você é criança, você convive com aquilo, porque é seu mundo. E ali você pega [...], a partir do momento que você cria consciência, que você vê as diferenças na sociedade, aí você começa a estranhar. [...] Porque todo lugar que eu fui, eu era o único, se eu não era, eu era um dos únicos. Na minha graduação, eu era o único aluno negro da sala. Acabei pegando uma matéria ou outra... então, tinha pessoas que eram negros, mais um conceito social de negro mais ameno, porque eram morenos, não tinham todas as características de negro. Eu não tenho todas elas, mais eu tenho características muito fortes e a principal, como nosso negro, a nossa característica negritude, ela é social, é como as pessoas te veem, então o fato de ter um cabelo "carapichado" essa eu considero a mais forte, o tom da pele é aliado ao cabelo. Se eu fosse a mesma pessoa e o tom de pele e o meu cabelo fosse liso, eu não era negro, eu era moreno. Então assim, na faculdade, eu acabei vendo algumas pessoas "morenas". A mais negra era eu. 
Considera o Programa UFGInclui de grande importância e pensa que deve ser ampliado.

\begin{abstract}
Na verdade, é o mínimo que a sociedade pode fazer. Eu sei que cotas não resolvem o problema, né? Mais eu vejo a política de cotas na sua essência, como uma coisa de longo prazo, né? Eu acho muito interessante as pessoas que atuam nessa parte aí de falar que nós, negros, nós precisamos ter exemplos, precisamos ter referências sociais na sociedade. [...] Então, da mesma forma eu preciso ter exemplos. Eu preciso ter vários Joaquins Barbosas aí no topo do poder, né? Até mesmo pra ter essa representatividade e mostrar para os demais que é possível chegar lá, né? E estar naquele lugar, também, buscando incluir mais pessoas. [...] Então não tem porque eu me calar, né? Ficar neutro numa discussão dessas é algo que eu julgo injusto.
\end{abstract}

Ainda que apresentem particularidades em razão de diferentes trajetórias de vida, alguns aspectos comuns podem ser apontados nos relatos de Lucas, Jackson, José, Samanta e Paulo.

Dos cinco alunos entrevistados, quatro moravam em cidades do interior do Estado e mudaram-se para a capital (Goiânia) para estudar. De acordo com os dados do questionário socioeconômico da UFG, cerca de 30\% dos alunos que ingressaram no primeiro vestibular de 2009 pelo Programa UFGInclui eram provenientes de cidades do interior e egressos de famílias trabalhadoras em atividades de baixa remuneração que investiram esforços para conseguir uma formação escolar satisfatória para os filhos. Ainda que não pudessem arcar com os custos de uma escolarização particular, buscaram formas de compensar os "prejuízos" por meio de bolsas de estudo ou escolas públicas de melhor qualidade ou, ainda, uma educação familiar centrada na intensa valorização da escola como meio de ascensão social.

Estudos têm discutido a importância atribuída pelas famílias de diferentes classes sociais à escola como meio de ascensão social e, mais especificamente, têm tratado a longevidade de estudantes pobres nas universidades (Romanelli, 1986, 1995; Sposito, 1989; Nogueira, Romanelli, Zago, 2000; Viana, 2005; Zago, 2006). A maioria deles apresenta como objetivos dos jovens e de suas famílias melhores condições de inserção no mercado de trabalho e, consequentemente, obtenção de salários mais elevados. Esse tem sido um empenho de famílias e estudantes pertencentes à classe empobrecida da população, ${ }^{4}$ que não dispõe de condições para custear uma trajetória de ensino básico em escolas particulares.

A configuração socioeconômica dos entrevistados é semelhante à dos demais estudantes do Programa UFGInclui que ingressaram em 2009. São sujeitos egressos de famílias trabalhadoras, cujos pais não tiveram oportunidade de realizar estudos prolongados. Dos cinco alunos entrevistados, apenas Lucas nunca trabalhou; os demais tentam conciliar o trabalho com os estudos na universidade, que não lhes oferece auxílio financeiro específico. Apenas Lucas pode contar com sua família, em especial com o empenho da mãe, para custear seus estudos. Desse modo, manter o propósito de realizar uma formação superior para os alunos entrevistados parece ser um desafio permanente. Essa condição impõe barreiras muitas 
vezes insuperáveis, principalmente em se tratando de jovens que, em suas vidas, dependeram e dependem do trabalho para se manter na escola.

Os alunos entrevistados, em muitos momentos da entrevista, expressaram a condição desfavorável de sua formação escolar. Todos se consideraram bons alunos no ensino básico, e esse é um aspecto que certamente os "autorizou" a prestar o vestibular de um curso concorrido em uma universidade pública. No entanto, foram unânimes em dizer da necessidade de retomar conteúdos que não foram trabalhados no ensino básico e de recuperar a frágil formação obtida. O "correr atrás" é um termo utilizado pelos alunos para dizer da necessidade de superar as lacunas existentes em sua formação. Mas, na verdade, esse termo diz mais: revela que a competição acirrada continua no cotidiano desses estudantes, que enfrentam, no seu dia a dia, dificuldades concretas para apresentar o desempenho requerido e se manter no curso.

Como afirma Zago (2006, p. 227), "a desigualdade de oportunidades de acesso ao ensino superior é construída de forma contínua e durante toda a história escolar dos candidatos". Ex-alunos de escolas públicas trazem a marca de uma educação básica que não contribui para garantir uma formação de qualidade. Assim, a decisão de prestar um vestibular competitivo em uma universidade federal, ainda que beneficiados por uma política de reserva de vagas, não é algo natural: configura-se um fato incomum, como um percurso antagônico, visto que a trajetória realizada não resulta em formação que os habilite a competir pelas vagas existentes com aqueles que cursaram escolas particulares, em sua maioria direcionadas à preparação para o vestibular.

Lucas relata que, quando chegou ao cursinho, foi uma surpresa perceber a precariedade da sua formação: "tinha um monte de coisa que eu não sabia". Jackson e Samanta, pela primeira vez em suas vidas escolares, tiveram reprovações. Quanto a José, ao analisar a condição elitista da escola brasileira, destaca a debilidade do ensino público, sobretudo nas áreas que são mais cobradas no exame vestibular dos cursos mais concorridos, como Ciências e Matemática, e reconhece que teve que estudar "por fora", como ele mesmo disse, para conseguir bons resultados no curso de Medicina.

Um traço marcante de todos os alunos entrevistados foi a análise crítica de suas chances objetivas de obterem a aprovação, mesmo que por meio do programa de inclusão. Com um histórico escolar que não possibilitava uma competição com os estudantes bem preparados pelos colégios de "tradição" na aprovação em vestibulares, todos tinham clareza dos limites que lhes eram impostos. Por isso, ao considerar a aprovação para o curso de Medicina quase uma "realização divina", José expressa o que Nogueira (2000) chama de "interiorização do improvável", que leva a maioria dos alunos de escolas públicas a não considerar a possibilidade de entrar na universidade pública antes mesmo de prestar o vestibular.

A surpresa da aprovação revela que o vestibular foi uma "tentativa" que não representou, de forma alguma, uma ação segura. Como relata Paulo, que prestou várias vezes o vestibular para Direito e nunca foi aprovado: decidiu 
fazer novamente "só para ver como estava o vestibular". E, para sua "surpresa total", foi aprovado. Para Samanta, a decisão foi difícil, pois não pensava ter chance alguma. Assim, ao se colocarem na posição de desvantagem, esses alunos consideram uma realidade objetiva que constitui suas vidas.

Oriundos de escolas públicas e de famílias cujos pais não cursaram ensino superior, mas cultivaram valores familiares que enfatizaram a importância dos estudos, esses estudantes constataram a fragilidade da formação que tiveram, mas indicaram também as condições de superar as dificuldades que enfrentam. Sob uma trajetória de sucesso na escola pública e reconhecendo os limites dessa formação, concomitantemente, e sob as promessas da inclusão e enfrentando cotidianamente os desafios para a permanência na universidade, os estudantes expõem as condições desiguais a que são submetidos em sua história. Entre os "excluídos", a exclusão se reproduz e a inclusão se efetiva de maneira desigual. Assim, os mecanismos de exclusão se repõem dentro das propostas das ações afirmativas que sugerem incluir todos.

\section{Referências bibliográficas}

MOEHLECKE, Sabrina. Ação afirmativa: história e debates no Brasil. Cadernos de Pesquisa, São Paulo, n. 117, p. 197-217, nov. 2002.

NOGUEIRA, Maria Alice; ROMANELLI, Geraldo; ZAGO, Nadir (Orgs.). Família e escola: trajetórias de escolarização em camadas médias e populares. Petrópolis: Vozes, 2000.

PINTO, Paulo Gabriel Hilu da R. Ação afirmativa, fronteiras raciais e identidades acadêmicas: uma etnografia das cotas para negros na Uerj. In: FERES JUNIOR, João; ZONISZEIN, Jonas (Orgs.). Ações afirmativas e universidade: experiências nacionais comparadas. Brasília: Ed. UnB, 2006.

ROMANELLI, Geraldo. Família de camadas médias: a trajetória da modernidade. 1986. Tese (Doutorado) - Universidade de São Paulo, São Paulo, 1986.

O significado da educação superior para duas gerações de famílias de camadas médias. Revista Brasileira de Estudos Pedagógicos, Brasília, v. 76, n. 184, p. 445-476, set./dez. 1995.

SAWAIA, Bader (Org.) As artimanhas da exclusão: análise psicossocial e ética da desigualdade social. Petrópolis: Vozes, 2006.

SEMINÁRIO UFGInclui, 2011, Goiânia. Apresentações do... Goiânia: UFG/Prograd, 2011. Disponível em: < http://www.prograd.ufg.br/sites/ prograd/pages/16214>. 
SPOSITO, Marília P. (Org.). O trabalhador-estudante: um perfil do aluno do curso superior noturno. São Paulo: Loyola, 1989.

UNIVERSIDADE FEDERAL DE GOIÁS (UFG). Programa UFGInclui: proposta aprovada no Conselho Universitário. 2008a. Disponível em: $<$ http://www.ufg.br/uploads/files/UFG-Inclui-01-08-08.pdf>. Acesso em: 10/2010.

UNIVERSIDADE FEDERAL DE GOIÁS (UFG). Conselho Universitário (Consuni). Resolução Consuni no 29/2008, de $1^{\circ}$ de agosto de 2008. Cria o Programa UFGInclui na Universidade Federal de Goiás e dá outras providências. 2008b. Disponível em: < http://www.prograd.ufg. br/sites/prograd/pages/16214>.

VIANNA, Maria José B. As práticas socializadoras familiares como locus de constituição de disposições facilitadoras de longevidade escolar em meios populares. Educação \& Sociedade, Campinas, v. 26, n. 90, p. 107125, jan./abr. 2005.

ZAGO, Nadir. Do acesso à permanência no ensino superior: percursos de estudantes universitários de camadas populares. Revista Brasileira de Educação, Campinas, v. 11, n. 32, p. 226-237, maio/ago. 2006.

Anita Cristina Azevedo Resende, doutora em Ciências Sociais pela Pontifícia Universidade Católica de São Paulo (PUC-SP), é professora titular da graduação e do Programa de Pós-graduação em Educação da Universidade Federal de Goiás (UFG).

aazeres@uol.com.br

Edna Mendonça Oliveira Queiroz, doutora em Educação pela Universidade Federal de Goiás (UFG), é professora adjunto da Faculdade de Educação dessa Universidade.

ednamqueiroz@gmail.com

Gina Glaydes Guimarães Faria, doutora em Educação pela Universidade Federal de Goiás (UFG), é professora adjunto da Faculdade de Educação dessa Universidade.

guima.fa@uol.com.br

Recebido em 21 de abril de 2011.

Aprovado em 8 de fevereiro de 2012. 